\title{
APUNTES PARA UN ESTUDIO CUANTITATIVO DE LAS NEGACIONES EN EL TEATRO GRIEGO
}

\author{
Felipe G. Hernández Muñoz \\ Universidad Complutense de Madrid \\ fhmunoz@filol.ucm.es
}

\section{RESUMEN}

Se estudian las proporciones entre las negaciones ou // $\mu$ ń en los principales autores del teatro griego (obra completa, piezas individuales y fragmentos) para detectar posibles diferencias. Palabras ClaVE: Proporciones, negaciones, ov̉, $\mu \eta \dot{n}$, teatro, griego, diferencias.

\section{ABSTRACT}

«Some notes on a quantitative study of negation in Greek drama». We study the proportions between the negations ov // $\mu$ n in the main authors of the Greek drama (whole work, individual pieces and fragments) to detect possible differences.

KEY WORDS: Proportions, negations, oủ, $\mu \eta$, Greek, drama, differences.

Este trabajo, que dedicamos a nuestra recordada Isabel, nace de una curiosidad lingüística y diferentes cuestiones con ella relacionadas: jlas dos principales negaciones en griego antiguo, la negación objetiva por excelencia, oủ, y la subjetiva, $\mu \eta$, mantienen una proporción estable, entre ellas y con referencia al resto de palabras, en los autores dramáticos griegos o existen diferencias objetivamente mensurables? Y, dentro de la primera negación, ¿̇también es uniforme entre ellos la proporción cuando la utilizan ante consonante (oủ) ${ }^{1}$ o cuando aparece ante vocal (oủ , oủX)? $\mathrm{Y}$, en este último caso, ¿es también constante la proporción ante vocal suave (oủ y aspirada (oủX)? Y, dentro de cada autor, ¿̨hay también diferencias destacables entre las diversas obras atribuidas según factores como la cronología o la temática? ¿Y entre su obra completa y la fragmentaria? ¿Y entre las obras auténticas y las de autenticidad discutida?

La existencia de un instrumento tan útil como el $T L G$ nos permite aventurarnos, aunque sea solo experimentalmente, en cuestiones que hasta hace pocos decenios eran prácticamente inabordables ${ }^{2}$. Con este trabajo pretendemos una primera aproximación a la cuestión inicialmente planteada y —ya lo podemos avanzar-la respuesta parece, en términos generales, afirmativa: a pesar de que autores como Esquilo, Sófocles, Eurípides y Aristófanes pertenecen a una concreta etapa del griego clásico (s. V-IV a. C.) 
y a un mismo género literario, el dramático (en la modalidad de tragedia los tres primeros y, en la de comedia, el cuarto) presentan entre sí diferencias cuantitativas destacables que, parece, no siempre resultan evidentes en una simple lectura, sino tras un exhaustivo recuento. En todo caso, queda abierta la cuestión para que otros colegas, desde otros puntos de vista, confirmen o no estas impresiones y, lo que es más importante, intenten hallar una explicación que, de momento, desborda los límites de este trabajo, limitado a la simple observatio y ordenación de los datos obtenidos.

Pues bien, tras el recuento de cada forma escrutada, el panorama general que resulta es el siguiente, de menor a mayor índice cada 1000 palabras en cada autor, primero en las piezas conservadas de forma completa y luego en las fragmentarias:

\section{OBRA COMPLETA ${ }^{3}$}

$\begin{array}{lllll} & \text { oủ } & \text { oủ+oủk+oủx } & \mu \eta \dot{n} & \text { oủ+oủk+oủx }+\mu \eta ́ \\ \text { ESQUILO } & 4.80^{4}(209) & 9.23(402) & 5.49(239) & 14.72(641) \\ \text { ARISTÓF. } & 6.57(679) & 13.10(1353) & 5.99(619) & 19.09(1972) \\ \text { EURÍPID. } & 6.83(1077) & 13.33(2102) & 6.28(990) & 19.62(3092) \\ \text { SÓFOCL. } & 7.51(459) & 14.37(878) & 7.92(484) & 22.30(1362)\end{array}$

${ }^{1}$ Hay algunos casos, muy pocos, en que esta negación en forma tónica, al final de frase y ante puntuación (oû), aparece ante vocal: no hay ejemplos en los trágicos, pero sí 3 en Aristófanes y 2 en Menandro. En los 42 ejemplos restantes de oủ tónica en el teatro griego, aparece ante consonante. En el caso de oük, los 80 ejemplos al final de frase y ante puntuación se encuentran todos ante vocal. Los escasísimos ejemplos de oủx, tónica ante puntuación, se dan todos ante vocal aspirada.

${ }^{2}$ Continúa en la senda de otros trabajos, también experimentales, que hemos realizado sobre "estilometría" y, más concretamente, "fonometría" (recuentos de sonidos) y "logometría" (recuentos de palabras), en distintos autores griegos con obras de autenticidad debatida (Hernández Muñoz, 2003, 2011, 2016 y 2017). La novedad, siempre relativa, de la metodología empleada nos permite aligerar las notas de citas de una extensa bibliografía para concentrarnos en el comentario de algunos datos presentados, que en este trabajo solo se ofrecen en su formulación más general, dejando para otra ocasión otros más parciales, sobre los que aquellos se sustentan.

${ }^{3}$ Hay que tener en cuenta el número total de palabras (las que están separadas por un espacio en blanco según el $T L G$, un dato más exacto que el del número de versos) que componen las piezas completas de cada autor:

ESQUILO: 43527

SÓFOCLES: 61069

EURÍPIDES: 157579

ARISTÓFANES: 103259

${ }^{4}$ Cada índice indica apariciones cada 1000 palabras. Por ejemplo, en el caso de las piezas completas atribuidas a Esquilo obtenemos el dato global (con diferencias entre las distintas obras) de casi 5 apariciones (4.8) de oủ cada 1000 palabras, y así sucesivamente. A continuación, entre paréntesis aparece el número total de ejemplos del término o términos en cuestión. Obviamente, los datos están tomados de las ediciones sobre las que el TLG reposa, auque creemos que las diferencias que pueden existir entre las diferentes ediciones no invalidarían el cuadro global obtenido. 
En cada columna, la progresión del índice (cada 1000 palabras), de menor a mayor, se produce según la misma secuencia de autores, pero el panorama cambia si los presentamos en forma de proporciones 5 :

\begin{tabular}{|c|c|}
\hline & oủ // oủ+oủk \\
\hline ARISTÓF. & $1.01: 1(679: 674)$ \\
\hline EURÍPID. & $1.05: 1(1077: 1025)$ \\
\hline ESQUILO & $1.08: 1(209: 193)$ \\
\hline SÓFOCL. & $1.09: 1(459: 419)$ \\
\hline & oú+oủk+oủx // $\mu \eta^{\prime}$ \\
\hline ESQUILO & $1.68: 1(402: 239)$ \\
\hline SÓFOCL. & $1.81: 1(878: 484)$ \\
\hline EURÍPID. & $2.12: 1(2102: 990)$ \\
\hline ARISTÓF. & $2.18: 1^{6}(1353: 619)$ \\
\hline & oủk // oủx \\
\hline ESQUILO & $5.22: 1(162: 31)$ \\
\hline EURÍPID. & $5.36: 1(864: 161)$ \\
\hline SÓFOCL. & $5.44: 1(354: 65)$ \\
\hline ARISTÓF. & $6.57: 1^{7}(585: 89)$ \\
\hline
\end{tabular}

\section{FRAGMENTOS 8}

En la obra fragmentaria atribuida, la secuencia de autores presenta ciertas "anomalías" que nos han llevado a presentar cada ítem por separado:

${ }^{5}$ Esto es, el número de oủ (ante consonante o puntuación fuerte) es un poco superior (679 en total) al de las apariciones ante vocal (674), lo que equivale 1.08: 1 (674 x 1.01=679), y así sucesivamente. dobla al de $\mu$ ń.

${ }^{6}$ Eurípides y Aristófanes serían los autores en que el número de oủ (con oủ+oủk) más que ante áspera.

${ }^{7}$ Aristófanes sería, pues, el único autor que más que sextuplica la forma ante vocal suave que

${ }^{8}$ También hay que tener aquí en cuenta el número total de palabras que componen el conjunto de la obra fragmentaria atribuida a cada autor:

ESQUILO: 41448

SÓFOCLES: 16125

EURÍPIDES: 39079

ARISTÓFANES: 16272 


\begin{tabular}{|c|c|}
\hline ESQUILO & $4.12(171)$ \\
\hline ARISTÓF. & $5.50(86)$ \\
\hline SÓFOCL. & $5.82(94)$ \\
\hline \multirow[t]{2}{*}{ EURÍPID. } & $5.88(230)$ \\
\hline & OỦ+oủK+oủx \\
\hline ESQUILO & $6.90(286)$ \\
\hline SÓFOCL. & 8.31 (134) \\
\hline ARISTÓF. & $10.00(164)$ \\
\hline \multirow[t]{2}{*}{ EURIIPID. } & $12.31(481)$ \\
\hline & $\mu \eta ́$ \\
\hline ESQUILO & $2.99(124)$ \\
\hline SÓFOCL. & $3.28 \quad(53)$ \\
\hline ARISTÓF. & $4.73(77)$ \\
\hline \multirow[t]{2}{*}{ EURÍPID. } & $5.57(218)$ \\
\hline & 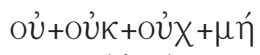 \\
\hline ESQUILO & 9.89 (410) \\
\hline SÓFOCL. & 11.59 (187) \\
\hline ARISTÓF. & $14.68(241)$ \\
\hline EURÍPID. & $17.88(699)$ \\
\hline
\end{tabular}

En efecto, si en la obra completa en cada negación o grupo de negaciones la secuencia de índices siempre era Esquilo < Aristófanes < Eurípides < Sófocles, en la fragmentaria la secuencia es (en el caso de $\mu$ í sola y en el global de negaciones oỦ+oỦK+ở $X+\mu \eta ́$ ): Esquilo < Sófocles < Aristófanes < Eurípides; en el caso de oủ sola y acompañada de oủ+oủk, Esquilo es el de menor índice y Eurípides el de mayor, pero en la sección intermedia varían: Aristófanes < Sófocles, y Sófocles < Aristófanes, respectivamente. Todo ello nos sugiere, como ya hemos apuntado, ciertas "anomalías" globales en la literatura dramática de tipo fragmentario que, unidas a otras de carácter "fonométrico" que hemos estudiado recientemente", nos ha llevado a postular dudas de autenticidad, al menos parcialmente, a falta de una razón satisfactoria que explique por qué en los fragmentos cambia ostensiblemente, en relación con las piezas completas del mismo autor, las proporciones entre oclusivas o entre negaciones, por ejemplo.

${ }^{9}$ Hernández Muñoz, 2016, especialmente 153-156. 
En cuanto a las proporciones entre esas negaciones, también el cuadro resultante en los fragmentos se aparta significativamente del esbozado para el conjunto de la obra completa — y por ende mayoritariamente auténtica — atribuida a cada autor dramático:

\begin{tabular}{|c|c|}
\hline & oủ // oủ+oủk \\
\hline EURÍPID. & $0.91^{10}: 1(230: 25$ \\
\hline ARISTÓF. & $1.10: 1(86: 78)$ \\
\hline ESQUILO & $1.48: 1(171: 115)$ \\
\hline СО人 & $2.35: 1(94: 40)$ \\
\hline & oủ+oủk+oưx // $\mu n^{\prime}$ \\
\hline ARIS & $2.12: 1(164: 77)$ \\
\hline EURÍPID. & $2.20: 1(481: 218)$ \\
\hline ESQUILO & $2.30: 1(286: 124)$ \\
\hline SÓFOCL. & $2.50: 1(134: 53)$ \\
\hline & oủk // o \\
\hline ESQUILO & $3.42: 1(89$ \\
\hline & $4.71: 1(33: 7)$ \\
\hline & $5.50: 1(66: 12)$ \\
\hline URÍP & $5.97: 1(215: 36)$ \\
\hline
\end{tabular}

\section{PIEZAS INDIVIDUALES}

Los cuadros anteriores no son sino el panorama global de cada autor, obtenido tras recuentos parciales en cada pieza que, por su carácter prolijo, no incluimos aquí. No obstante, un estudio como el que nos proponemos quedaría claramente incompleto si no descendiéramos al detalle de algunas piezas concretas, aunque solo sea a título de ejemplo. Nos vamos, pues, a limitar a las que globalmente presentan índices extremos en cada autor, reservando cuestiones más específicas para trabajos posteriores.

Así, entre las atribuidas a Esquilo Prometeo presenta los índices más elevados $^{11}$, también cada 1000 palabras, de uso de oủ (6.21), oủ+oủk+oủx (11.95)

${ }^{10}$ En todos los datos presentados es la única vez que el índice de oủ es inferior al otro con el que se le compara.

${ }^{11}$ En otro trabajo (Hernández Muñoz, 2003) también destacamos la singularidad de la pieza por su número de hápax relativos y su perfil fonométrico, distinto también de las otras obras conservadas de Esquilo. 


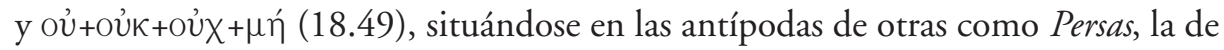
cronología más temprana entre las conservadas (3.71, 7.08 y 8.85, respectivamente) o Coéforas (3.02, 6.20 y 10.40, respectivamente). En el caso de Sófocles, la pieza que parece sobresalir por sus índices elevados es Electra $(9.30,16.47$ y 24.21 , respectivamente) y la que lo hace por sus bajos índices es Traquinias $(6.04,11.29$ y 18.55). En Eurípides, mención especial por sus índices relativamente más altos merece Heraclidas $(10.53,20.17$ y 28.45$)$, en tanto que Fenicias ocuparía la parte más baja (5.15, 10.49 y 14.60). Finalmente, en el comediógrafo Aristófanes, destacamos los altos índices de Lisístrata (8.47, 14.91 y 22.59) y los bajos de Aves (16.53) y Nubes (17.20)

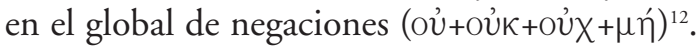

Por supuesto, el cuadro es más abigarrado que los retazos generales que aquí hemos podido esbozar a manera de simples "apuntes". Por ejemplo, en Esquilo deberían quizá destacarse los índices relativamente altos de Euménides. En Sófocles, los también altos de Filoctetes, tanto el global de todas las negaciones (24.17), como el parcial de $\mu$ í sola (9.58, el más elevado de todas las tragedias de Sófocles). Entre las atribuidas a Eurípides es interesante el alto índice de oủ (9.84. el segundo tras el de Heraclidas) en el discutido Cíclope, los también muy elevados — los más altos entre todas las tragedias de Eurípides- de Medea, tanto en el global de todas las negaciones (32.64) como en el parcial de $\mu$ ń sola (19.77), que contrastan con los relativamente bajos de Suplicantes (5.43 en oủ y 11.52 si añadimos oủ+oủK). En Aristófanes merecería asimismo destacarse el elevado índice de oủ en Ranas (8.31, el segundo más elevado tras el de Lisistrata), que se aparta de los relativamente bajos de Avispas (5.20) y Nubes (5.35), pieza que, entre todas las aristofánicas, también tiene el segun-

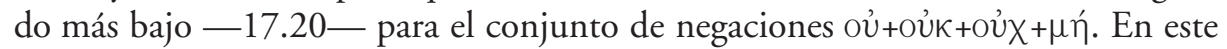
último ítem, las antípodas estarían en la ya citada Lisistrata (22.59) y en Asambleistas (22.38). Un estudio más pormenorizado, en el que ahora no podemos entrar, nos podría dar pistas sobre si estos cambios cuantitativos en la aparición y proporción de estas negaciones pueden responder a cuestiones de cronología, evolución, al carácter de la pieza en cuestión (por ejemplo, en el caso de Lisistrata y Asambleístas, el propio sentido de las obras, con el reiterado "no" de las mujeres a la guerra y, en general, al orden impuesto por los varones, podría explicar en parte esa abundancia relati-

${ }^{12}$ Ofrecemos el número de ejemplos debajo de las negaciones, sobre el total de palabras (entre paréntesis), de cada pieza mencionada en esta sección:

$\begin{array}{lccc} & \text { oủ } & \text { Oủ+oủk+oủx } & \text { oủ+oủk+oủx }+\mu \text { ń } \\ \text { PROMETEO (6271) } & 39 & 75 & 116 \\ \text { PERSAS (5647) } & 21 & 40 & 50 \\ \text { COÉFORAS (5959) } & 18 & 37 & 62\end{array}$


va de negaciones), a otros factores o si, por el contrario, son simplemente aleatorios $\mathrm{y}$ sin verdadera trascendencia ${ }^{13}$.

\section{BIBLIOGRAFÍA CITADA}

Hernández Muñoz, Felipe G. (2003): "La autenticidad de Prometeo Encadenado a la luz de las frecuencias lingüísticas”, en J. María NiETO IbÁÑEz (coord.), Lógos Hellenikós. Homenaje al prof. Gaspar Morocho, Universidad de León, vol. 1, pp. 149-157.

_ (2011): "La fonometría y otros criterios lingüísticos de autenticidad en literatura griega", en Javier MARTínez (ed.), Fakes and Forgers of Classical Literature, Madrid, pp. 137-144.

${ }^{13}$ Presentamos ahora el número total de palabras que componen cada obra aludida en este apartado, el número de documentaciones de cada negación y, a continuación, entre paréntesis, su índice relativo de empleo, siempre cada 1000 palabras, destacando algún dato que nos parece relevante:

\begin{tabular}{|c|c|c|c|c|}
\hline & oủ & oủ+oủK+oủX & $\mu \eta ́$ & oủ +oủK+oủ $X+\mu$ \\
\hline $\begin{array}{l}\text { EUMÉNIDES } \\
(5733)\end{array}$ & $34(5.93)$ & $59(10.29)$ & $41(7.15)$ & $100(17.44)$ \\
\hline $\begin{array}{l}\text { FILOCTETES } \\
(8977)\end{array}$ & $76(8.46)$ & $131(14.59)$ & $86(9.58)$ & $217(24.17)$ \\
\hline $\begin{array}{l}\text { CÍCLOPE } \\
(4469)\end{array}$ & $44(9.84)$ & $64(14.32)$ & $22(4.92)$ & $86(19.24)$ \\
\hline $\begin{array}{l}\text { MEDEA } \\
(8394)\end{array}$ & $51(6.07)$ & $108(12.86)$ & $166(19.77)$ & $274(32.64)$ \\
\hline $\begin{array}{l}\text { SUPLICANTES } \\
(7548)\end{array}$ & $41(5.43)$ & $87(11.52)$ & $46(6.09)$ & $133(17.62)$ \\
\hline $\begin{array}{l}\text { RANAS } \\
(10108)\end{array}$ & $85(8.31)$ & $140(13.94)$ & $68(6.72)$ & $208(20.57)$ \\
\hline $\begin{array}{l}\text { AVISPAS } \\
(10560)\end{array}$ & $55(5.20)$ & $128(12.12)$ & $80(7.57)$ & 208 (19.69) \\
\hline $\begin{array}{l}\text { NUBES } \\
(10463)\end{array}$ & $56(5.35)$ & $132(12.61)$ & $48(4.58)$ & $180(17.20)$ \\
\hline $\begin{array}{l}\text { LISÍSTRATA } \\
(8853)\end{array}$ & 75 (8.47) & $132(14.91)$ & $68(6.72)$ & $200(22.59)$ \\
\hline $\begin{array}{l}\text { ASAMBLEÍSTAS } \\
(8444)\end{array}$ & $59(6.98)$ & $113(13.38)$ & $76(9.00)$ & $189(22.38)$ \\
\hline
\end{tabular}


(2016): "Apuntes para un perfil fonométrico de autor en el teatro griego: el problema de la literatura fragmentaria", en EYIIOIKI $\Lambda O N A N \Theta O \Sigma$. Estudios sobre teatro griego en homenaje a Antonio Melero, Studia Philologica Valentina 18 (N.S. 15): 147-158.

(2017): "Notas de frecuencia en las oclusivas del griego antiguo (y sobre el sistema fonético en su conjunto) con implicaciones en cuestiones de autenticidad literaria", en J. A. ÁlVAREZ-PEDROSA et alii (eds.), Ratna. Homenaje a la Profa Julia Mendoza, Madrid, pp. 225-232. 